\title{
TOXICITY OF NITRAZEPAM IN THE ELDERLY: A REPORT FROM THE BOSTON COLLABORATIVE DRUG SURVEILLANCE PROGRAM
}

\author{
D.J. GREENBLATT \& MARCIA D. ALLEN \\ Boston Collaborative Drug Surveillance Program, Boston University Medical Center; and the \\ Clinical Pharmacology Unit, Massachusetts General Hospital, Boston, USA.
}

1 To assess the potential hazards of nitrazepam therapy of insomnia in the elderly, adverse reactions to nitrazepam were studied in 2111 hospitalized medical patients who received the drug.

2 Manifestations of unwanted central nervous system (CNS) depression (such as drowsiness or 'hangover') were reported in 49 nitrazepam recipients (2.3\%), and signs of unwanted CNS stimulation (such as nightmares, insomnia, agitation, etc.) in $15(0.7 \%)$. None of the adverse reactions were considered serious.

3 Physician-rated clinical efficacy of nitrazepam was not related to dose, but the frequency of both types of adverse reactions increased significantly at higher daily doses. CNS depression also was significantly more frequent in the elderly, being reported in $11 \%$ of those aged 80 years or older, whereas the frequency of CNS stimulation was not correlated with age.

4 The effect of age on the reported rate of unwanted CNS depression was most striking at high doses. Among patients aged 80 years or over whose daily dose averaged $10 \mathrm{mg}$ or more, $55 \%$ experienced unwanted CNS depression attributed to nitrazepam.

5 Low doses of nitrazepam are safe for elderly individuals, but the elderly are readily susceptible to excessive CNS depression at high doses. The findings suggest that there is little reason to exceed $5 \mathrm{mg}$ doses of nitrazepam for most patients, particularly those who are elderly.

\section{Introduction}

The extensive prescribing of psychotropic drugs for elderly patients has generated considerable concern (Learoyd, 1972, 1974; Dawson-Butterworth, 1970; Chapman, 1976). Nitrazepam, a 1,4-benzodiazepine derivative, is extensively used as a hypnotic agent throughout the eastern hemisphere. The sleep-inducing efficacy and relative safety of nitrazepam are well established (Greenblatt \& Shader, 1974), but recent reports suggest that the drug presents a hazard to certain elderly individuals (Evans \& Jarvis, 1972; Harenko, 1975; Castleden, George \& Mercer, 1977). Previous studies from the Boston Collaborative Drug Surveillance Program (BCDSP) indicate an increased frequency of adverse reactions to three other benzodiazepine derivatives-chlordiazepoxide, diazepam and flurazepam-in elderly patients (Boston Collaborative Drug Surveillance Program, 1973; Greenblatt, Allen \& Shader, 1977). The present report assesses the influence of age upon patterns of clinical toxicity attributed to nitrazepam among a large series of hospitalized medical patients who received the drug.

\section{Methods}

The scope and operation of the Boston Collaborative Drug Surveillance Program (BCDSP) have been described previously (Jick, 1974; Allen \& Greenblatt, 1975; Miller \& Greenblatt, 1976). Trained nursemonitors stationed on medical wards use standardized self-coding sheets to record information on consecutively admitted patients. Data are collected on patient characteristics, diagnoses, the therapeutic efficacy of all drugs administered, details of dosage, and duration of therapy. When drug therapy is instituted, the prescribing physician is interviewed to determine the therapeutic indications; reasons for termination of therapy and descriptions of possible adverse reactions are recorded as well. For each suspected adverse reaction, the attending physician judges the likelihood that the drug caused the adverse reaction. An independent second judgement is later rendered by a clinical pharmacologist who reviews the case.

This report is based on data accumulated between 1969 and 1976 on 11,000 hospitalized medical 
patients in Israel, Scotland, New Zealand, Germany and Italy, of whom 2111 (19.2\%) received nitrazepam.

\section{Results}

\section{Patient characteristics}

The mean age of the 2111 nitrazepam recipients was 57 years, and nearly $50 \%$ were aged 60 years or older (Table 1). Only 5\% died while in the hospital (Table 1). Cardiovascular disease was the primary (first) diagnosis in $51 \%$ of patients.

\section{Nitrazepam therapy}

Insomnia was the indication for nitrazepam therapy in nearly $100 \%$ of cases. Thirty per cent of nitrazepam recipients also received concurrent daytime therapy with an antianxiety agent, such as chlordiazepoxide, diazepam or phenobarbital (Table 2). The total quantity of nitrazepam administered during hospitalization varied widely; $28 \%$ of patients received

Table 1 Characteristics of nitrazepam recipients

\begin{tabular}{|c|c|}
\hline Characteristic & $\begin{array}{c}\% \text { of } \\
\text { patients }\end{array}$ \\
\hline $\begin{array}{l}\text { Age (years) } \\
\text { Less than } 30 \\
30 \text { to } 39 \\
40 \text { to } 49 \\
50 \text { to } 59 \\
60 \text { to } 69 \\
70 \text { to } 79 \\
80 \text { or older }\end{array}$ & $\begin{array}{r}7.3 \\
9.1 \\
13.5 \\
20.5 \\
29.9 \\
16.2 \\
3.4\end{array}$ \\
\hline $\begin{array}{l}\text { Sex } \\
\text { Male } \\
\text { Female }\end{array}$ & $\begin{array}{l}51.1 \\
48.9\end{array}$ \\
\hline $\begin{array}{l}\text { Survival } \\
\text { Survived } \\
\text { Died }\end{array}$ & $\begin{array}{r}95.3 \\
4.7\end{array}$ \\
\hline $\begin{array}{l}\text { Duration of hospitalization (day } \\
\text { Less than } 10 \\
10 \text { to } 19 \\
20 \text { or more }\end{array}$ & $\begin{array}{l}34.5 \\
44.3 \\
21.1\end{array}$ \\
\hline $\begin{array}{l}\text { Admission value of blood } \\
\text { urea nitrogen }(\mathrm{mg} / 100 \mathrm{ml}) \\
\text { Less than } 25 \\
25 \text { to } 49 \\
50 \text { or more } \\
\text { Unknown or unspecified }\end{array}$ & $\begin{array}{r}77.9 \\
15.9 \\
4.5 \\
1.7\end{array}$ \\
\hline $\begin{array}{l}\text { History of nitrazepam use } \\
\text { prior to admission } \\
\text { Yes } \\
\text { No } \\
\text { Unknown or unspecified }\end{array}$ & $\begin{array}{r}13.3 \\
84.2 \\
2.5\end{array}$ \\
\hline
\end{tabular}

a total dose of less than $20 \mathrm{mg}$, but $26 \%$ received $100 \mathrm{mg}$ or more (Table 2). Since most individuals received the drug on an intermittent or p.r.n. basis, it was useful to compute for each patient an 'average' daily dose, as the quotient of the total dose and the number of days of therapy. The average daily dose calculated by this method was less than $5 \mathrm{mg}$ per day in $30 \%$ of cases (Table 2).

The clinical efficacy of nitrazepam, as judged by attending physicians, was unsatisfactory in $7.5 \%$ of cases. Unsatisfactory ratings were similar in frequency regardless of the size of the administered dose (Table 2).

\section{Adverse reactions}

Adverse reactions were attributed to nitrazepam in 72 $(3.4 \%)$ of the 2111 recipients. In all instances both the attending physician and the clinical pharmacologist who later reviewed the case judged that the adverse reaction was probably or definitely due to nitrazepam, either entirely or in part. Forty-nine of the 72 adverse reactions were manifestations of unwanted central

Table 2 Characteristics of nitrazepam therapy

\begin{tabular}{|c|c|}
\hline Characteristic & $\begin{array}{c}\% \text { of } \\
\text { patients }\end{array}$ \\
\hline $\begin{array}{l}\text { Total dose }(\mathrm{mg}) \\
\text { Less than } 10 \\
10 \text { to } 19 \\
20 \text { to } 39 \\
40 \text { to } 59 \\
60 \text { to } 99 \\
100 \text { or more } \\
\text { Unknown }\end{array}$ & $\begin{array}{r}14.3 \\
14.1 \\
16.6 \\
11.5 \\
17.5 \\
25.8 \\
0.2\end{array}$ \\
\hline $\begin{array}{l}\text { Average deily dose }{ }^{*}(\mathrm{mg}) \\
\text { Less than } 2.5 \\
2.5 \text { to } 4.99 \\
5.0 \text { to } 9.99 \\
10.0 \text { or more } \\
\text { Could not be calculated }\end{array}$ & $\begin{array}{r}15.5 \\
14.7 \\
41.4 \\
28.1 \\
0.2\end{array}$ \\
\hline $\begin{array}{l}\text { Physicians' judgement of effici } \\
5 \text {-mg dose } \\
\text { Satisfactory } \\
\text { Unsatisfactory }\end{array}$ & $\begin{array}{r}93.5 \\
6.5\end{array}$ \\
\hline $\begin{array}{l}\text { 10-mg dose } \\
\text { Satisfactory } \\
\text { Unsatisfactory }\end{array}$ & $\begin{array}{r}91.3 \\
8.7\end{array}$ \\
\hline $\begin{array}{l}\text { Coadministration of daytime } \\
\text { antianxiety agents } \\
\text { Yes } \\
\text { No }\end{array}$ & $\begin{array}{l}30.4 \\
69.6\end{array}$ \\
\hline
\end{tabular}


nervous system (CNS) depression (Table 3); 15 other adverse events appeared to represent CNS stimulation, and included nightmares, hallucinations, insomnia, agitation, and hyperactivity. Cutaneous reactions were attributed to nitrazepam in five cases, and other adverse effects in three cases. In no instance did attending physicians judge the unwanted effect to be serious or life-threatening. Ten of the 72 patients eventually died, but nitrazepam was not implicated in any of these deaths. Fifty-six of the 72 adverse reactions were reported within 3 days of the beginning of nitrazepam therapy. In 51 cases the drug was discontinued as the result of the adverse reactions, and in another 13 cases the dose was decreased. In the other eight, no specific therapeutic measure was taken.

\section{Factors influencing the frequency of adverse reactions}

Dose The frequency of unwanted CNS depression and CNS stimulation both became significantly higher at larger daily doses (Figure 1). CNS depression was reported in only one of 639 patients $(0.2 \%)$ receiving less than $5 \mathrm{mg}$ per day; this increased to $5.9 \%$ (35 of 593) of those receiving $10 \mathrm{mg}$ or more $\left(x^{2}=49.3\right.$, d.f. $=2, P<0.001)$. Likewise, the frequency of CNS stimulation increased from zero at the low dose level to $1.5 \%$ ( 9 of 593 patients) at the high dose $\left(\chi^{2}=10.0\right.$, d.f. $=2, P<0.01$ ) (Figure 1). When the frequency of adverse reactions was examined simply in relation to the size of the unit dose, the findings were very similar. Of 1195 patients for whom a 5-mg dose was ordered, $13(1.1 \%)$ experienced unwanted CNS depression, and $4(0.3 \%)$ experienced CNS stimulation, attributed to nitrazepam. Among the 895 individuals for whom $10 \mathrm{mg}$ nitrazepam was ordered, $36(4.0 \%)$ and 11 (1.2\%) experienced unwanted drug-attributed CNS depression and stimulation, respectively. The number of cutaneous and other adverse reactions attributed to nitrazepam (Table 3) was not sufficient to evaluate the effect of dose.

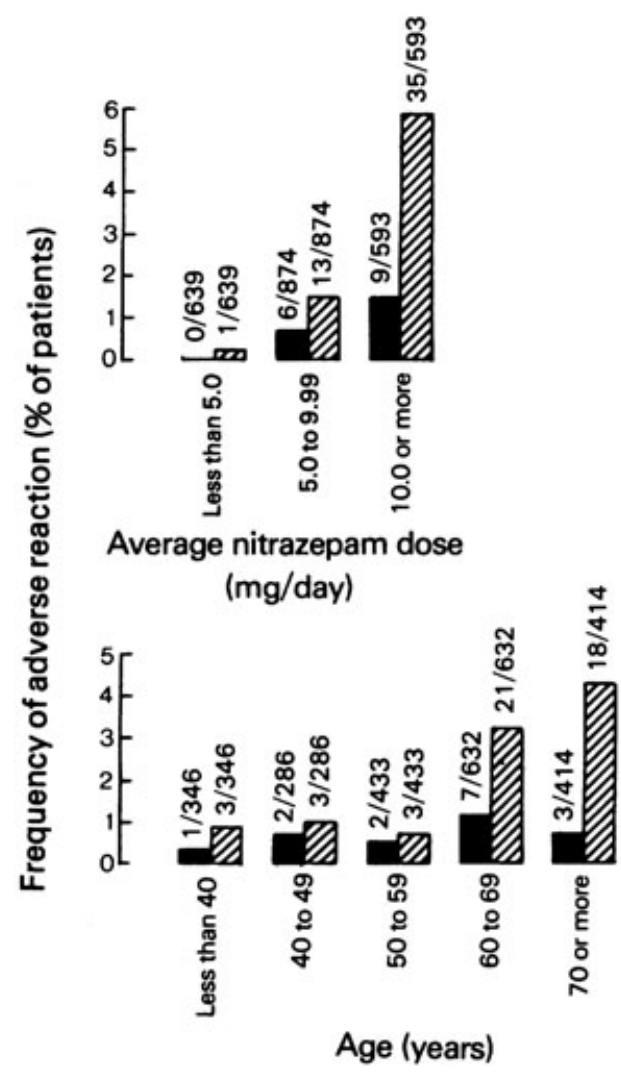

Figure 1 Relation of daily dose (above) and age (below) to the frequency of unwanted CNS stimulation $(\square)$ and depression $(\mathbb{Z})$ attributed to nitrazepam.

Age Unwanted CNS depression became significantly more frequent with increasing age $\left(x^{2}>50\right.$, d.f. $=4$, $P<0.001$ ) (Figure 2. The frequency of CNS depression attributed to nitrazepam increased from $0.9 \%$ ( 4 of 346 ) for those aged less than 40 years to

Table 3 Adverse reactions attributed to nitrazepam

$\begin{array}{lcc}\text { Adverse reaction } & \begin{array}{c}\text { Number of } \\ \text { patients }\end{array} & \text { \% of patients } \\ \begin{array}{c}\text { CNS depression } \\ \text { (drowsiness, fatigue, confusion, ataxia) }\end{array} & 49 & 2.3 \\ \begin{array}{c}\text { CNS stimulation or excitation } \\ \text { (nightmares, hallucinations, insomnia, agitation) }\end{array} & 15 & 0.7 \\ \begin{array}{c}\text { Cutaneous reactions } \\ \text { (rash, pruritis) }\end{array} & 5 & 0.2 \\ \begin{array}{c}\text { Other adverse reactions } \\ \text { (headache, gastrointestinal disturbances) } \\ \text { Total }\end{array} & 3 & 0.1 \\ \quad 72 & 3.4\end{array}$




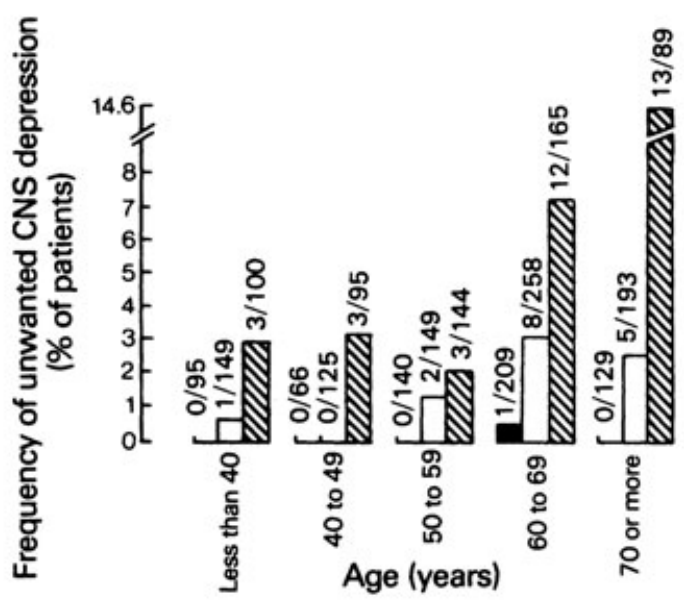

Figure 2 Relation of daily dose (a less than $5 \mathrm{mg} /$ day; $\square$ 5.0-9.99 mg/day; 10.0 or more $\mathrm{mg} /$ day) to the frequency of unwanted CNS depression attributed to nitrazepam, with the population stratified according to age.

$4.4 \%$ (18 of 414 ) for those 70 years or older. Among 72 individuals aged 80 or older, $8(11.1 \%)$ experienced unwanted CNS depression attributed to nitrazepam. Adverse reactions manifested as unwanted CNS stimulation, however, were not significantly correlated with age $\left(X^{2}=2.67\right.$, d.f. $=4$, NS) (Figure 1).

Interaction of dose and age Stratification of dosage levels within each age group indicated that the influence of dose upon the frequency of unwanted CNS depression was most obvious in the elderly (Figure 2). At average doses of less than $5 \mathrm{mg}$ per day, the frequency of CNS depression did not exceed $0.5 \%$ of patients regardless of age. However, at average doses of $10 \mathrm{mg}$ per day or more, unwanted CNS depression increased in frequency from $3.0 \%$ (3 of 100) among those aged 40 or less to $15 \%$ (13 of 89 ) for those aged 70 or older, and to $55 \%$ (6 of 11) for individuals 80 years or older. A similar trend was observed in the frequency of CNS stimulation attributed to nitrazepam, but the association was not striking.

Other factors Impairment of renal function, as judged by abnormal levels of blood urea nitrogen (BUN) on admission, was associated with a significantly higher frequency of adverse reactions to nitrazepam (Table 4). Unwanted effects also were significantly more common among patients with long hospitalizations and in those who died (Table 4). The frequency of adverse reactions to nitrazepam was not significantly correlated with sex, body weight, coadministration of antianxiety agents while hospitalized, or to prior outpatient exposure to nitrazepam.

\section{Discussion}

Recognition of potential unwanted effects of nitrazepam and of factors predisposing to toxicity are important to ensure its appropriate use in clinical medicine. The present study summarizes adverse reactions attributed to nitrazepam among 2111 intensively-monitored hospitalized medical patients who received this drug for the treatment of insomnia.

Table 4 Factors influencing the frequency of adverse reactions to nitrazepam

Factor

\section{Number of}

patients

\section{Admission value of blood urea nitrogen $(\mathrm{mg} / 100 \mathrm{ml})$ " $t$ \\ Less than 25 \\ 25 to 49 \\ 50 or more}

Days in hospita/ $\$$

Less than 10

10 to 19

20 or more

Surviva/**

Survived
1645

335

96

729

936

446

2011

100
Number with

adverse reactions

(\%)

- No value available in 35 cases, including one with an adverse reaction.

$\dagger \chi^{2}=9.2$, d.f. $=2, P \simeq 0.01$.

$\mp \chi^{2}=9.4$, d.f. $=2, P<0.01$.

$* x^{2}=13.8$, d.f. $=1, P<0.001$. 
Estimates of toxicity are derived from clinical judgements made by attending physicians. These judgements are generally based upon an understanding of the pharmacologic properties of the drug, as well as the time relation between drug exposure and the unwanted clinical event (Miller \& Greenblatt, 1976). An independent evaluation of each episode by a clinical pharmacologist was used to support the judgements of attending physicians.

The results of this survey suggest that adverse reactions to nitrazepam among hospitalized medical patients are infrequent and relatively minor. Unwanted effects were attributed to the drug in only $3.4 \%$ of recipients. None were considered serious, and in all cases the patients recovered spontaneously or following drug discontinuation or reduction of dosage. Unwanted CNS depression, such as drowsiness or hangover, was the manifestation of toxicity in 49 of these 72 cases (2.3\% of recipients). This is very close to the incidence of such reactions (2.8\%) among 2542 recipients of flurazepam reported previously (Greenblatt et al., 1977). However, 15 nitrazepam recipients $(0.7 \%)$ experienced CNS stimulation, such as nightmares, insomnia, hallucinations or agitation. This contrasts with the flurazepam study (Greenblatt et al., 1977), in which only 5 of 2542 patients $(0.2 \%)$ experienced nightmares, and none experienced hallucinations, agitation, or insomnia attributed to the drug. The BCDSP data on chlordiazepoxide and diazepam likewise reveals a frequency of drugattributed CNS stimulation not exceeding $0.3 \%$ of patients (Miller \& Greenblatt, 1976). Nightmares have been associated with nitrazepam therapy in several reports in the literature (Meares, Mills \& Oliver, 1972; Taylor, 1973; Girdwood, 1973; Goossens, Bulckaert \& Wakeling, 1973). Furthermore, 'paradoxical' CNS stimulation, including agitation, hyperactivity, and aggressive behavior, is commonly observed among children receiving anticonvulsant therapy with clonazepam, a 7-nitro-substituted benzodiazepine derivative closely related to nitrazepam in structure (Browne, 1976). The findings suggest that nitrosubstitution at the 7-position may render benzodiazepine derivatives more likely to produce unwanted CNS stimulation.

Unsatisfactory hypnotic efficacy of nitrazepam was reported in only $7.5 \%$ of cases in which a judgement of efficacy was made. The frequency of unsatisfactory ratings did not become smaller as the dose increased. Again, this contrasts with the results of the flurazepam study (Greenblatt et al., 1977), in which unsatisfactory ratings were significantly more frequent among patients receiving lower doses. It should be emphasized that the present study was not a prospective controlled trial, and the findings may in part reflect a tendency for physicians to administer higher doses of nitrazepam to patients with more severe insomnia. However, it is likely that the hypnotic efficacy of 5 and $10 \mathrm{mg}$ doses of nitrazepam is approximately equivalent. This is consistent with controlled clinical trials which demonstrate only subtle differences in hypnotic efficacy between the two dose levels of nitrazepam (le Riche, Csima \& Dobson, 1966; Malpas, Rowan \& Joyce, 1970; Malpas, Legg \& Scott, 1974).

On the other hand, the two major types of adverse reactions to nitrazepam clearly were dose-related in frequency. Numerous clinical studies demonstrate an increased frequency of unwanted CNS depression and/or impairment of psychomotor performance at higher doses of nitrazepam (le Riche et al., 1966; Malpas \& Joyce, 1969; Malpas et al., 1970; Walters \& Lader, 1971; Malpas, 1972; Adams, 1974; Borland \& Nicholson, 1974; Momose, Ishii \& Kuge, 1976). We observed that unwanted CNS stimulation also became more frequent at higher nitrazepam doses, suggesting that such reactions are not necessarily unpredictable or 'idiosyncratic'.

Unwanted CNS depression attributed to nitrazepam was substantially more frequent among the elderly, particularly in patients aged 70 years or older. A similar association of toxicity with increasing age has been reported in BCDSP studies of other benzodiazepine derivatives (chlordiazepoxide (BCDSP, 1973), diazepams (BCDSP, 1973), and flurazepam (Greenblatt et al., 1977)), but has not been observed in the BCDSP data for nonbenzodiazepine hypnotics such as chloral hydrate and barbiturates (Miller \& Greenblatt, 1976). Examination of the interaction of dose and age indicated that the higher incidence of nitrazepam-attributed CNS depression in the elderly was evident only at high doses of nitrazepam. At low doses, such reactions were rare regardless of age. The hazards of nitrazepam in the elderly, particularly at high doses, have been observed by others (Evans \& Jarvis, 1972; Harenko, 1975; Castleden et al., 1977). There appears to be little reason to initiate nitrazepam therapy with $10 \mathrm{mg}$ doses in most patients, and certainly not in the elderly. Doses of $5 \mathrm{mg}$ provide approximately equivalent hypnotic efficacy, with a substantially reduced frequency of unwanted drowsiness, hangover, and other manifestations of undesired CNS depression.

In contrast to adverse reactions related to CNS depression, age per se had little influence on the frequency of unwanted CNS stimulation. According to traditional teaching, elderly individuals are particularly susceptible to 'paradoxical' stimulation due to hypnotic drug administration (Gibson, 1966; Dawson-Butterworth, 1970; Learoyd, 1972). Our data on nitrazepam, however, suggest that dose rather than age is the major determinant of such reactions.

The present study does not establish whether the increased toxicity of nitrazepam in the elderly is due to a greater sensitivity of the ageing brain to effects of the drug, or to age-related changes in pharmacokinetics which lead to greater accumulation of the drug in brain. Studies of other benzodiazepines suggest that 
important pharmacokinetic changes can occur with age. Clearance of chlordiazepoxide is reduced in elderly as opposed to young male volunteers (Shader, Greenblatt \& Harmatz, 1977). Studies of diazepam reveal longer values of elimination half-life associated with age, but no significant age-related change in clearance (Klotz, Avant \& Hoyumpa, 1975). Nitrazepam clearance is accomplished largely by reduction of the 7-nitro substitution, followed by acetylation (Greenblatt \& Shader, 1974; Reider \& Wendt, 1973). The acetylation reaction is genetically polymorphic (Karin \& Price-Evans, 1976), but a recent study suggested that age as such had no significant influence on nitrazepam elimination (Castleden et al., 1977).

Adverse reactions to nitrazepam were more frequent among individuals who died, in those with long hospitalizations, and in those with elevated blood urea nitrogen concentrations on admission. These associations probably reflect a general tendency for adverse drug reactions to occur more frequently among more seriously ill patients (Miller \& Greenblatt, 1976). Since renal clearance contributes very little to the total metabolic clearance of nitrazepam, it is unlikely that renal insufficiency in itself causes increased accumulation of nitrazepam. However, renal disease can influence drug distribution, possibly through a change in the extent of drug protein-binding (Koch-Weser \& Sellers, 1976).

Of interest are the five cutaneous reactions attributed to nitrazepam. A previous study designed

\section{References}

ADAMS, R.G. (1974). Pre-sleep ingestion of two hypnotic drugs and subsequent performance. Psychopharmacologia, 40, 185-190.

ALLEN, M.D. \& GREENBLATT, DJ. (1975). Role of nurse and pharmacist monitors in the Boston Collaborative Drug Surveillance Program. Drug Intel. Clin. Pharmac. $9,648-654$.

ARNDT, K.A. \& JICK, H. (1976). Rates of cutaneous reactions to drugs: a report from the Boston Collaborative Drug Surveillance Program. J. Am. med. Ass., 235, 918-923.

BORLAND, R.G. \& NICHOLSON, A.N. (1975). Comparison of the residual effects of two benzodiazepines (nitrazepam and flurazepam hydrochloride) and pentobarbitone sodium on human performance. Br. J. clin. Pharmac., 2, 9-17.

BOSTON COLLABORATIVE DRUG SURVEILLANCE PROGRAM (1973). Clinical depression of the central nervous system due to diazepam and chlordiazepoxide in relation to cigarette smoking and age. $N$. Engl. J. Med., 288, 277-280.

BROWNE, T.R. (1976). Clonazepam: a review of a new anticonvulsant drug. Arch. Neurol., 33, 326-332.

CASTLEDEN, C.M., GEORGE, C.F. \& MARCER, D. (1977), Increased sensitivity to nitrazepam in old age. $\mathrm{Br}$. med. J., 1, 10-12. specifically to elucidate rates of cutaneous reactions of drugs revealed an even higher rate of about six cutaneous reactions per 1000 recipients of nitrazepam (Arndt \& Jick, 1976), suggesting that many such reactions are attributed to other drugs given concurrently. Other benzodiazepines without 7-nitro substitution are associated with substantially lower rates of cutaneous reactions (Arndt \& Jick, 1976).

The Boston Collaborative Drug Surveillance Program is supported by United States Public Health Service Contract GM-4-2148 from the National Institute of General Medical Sciences (NIGMS); and in part by grants from the United States Food and Drug Administration; the Hadassah Medical Organization; the Kupat-Holim; Auckland Hospital, New Zealand; the Israeli Ministry of Health; the Canadian Food and Drug Directorate; the Roger Williams General Hospital (Brown University NIGMS grant no. GM165-38-02); the Scottish Home and Health Department; and Hoffmann-LaRoche, Inc. A list of participating hospitals can be found in Miller \& Greenblatt (1976) and Allen \& Greenblatt (1975).

Dr Greenblatt is supported in part by grant MH-12279 from the United States Public Health Service. Ms Allen is the recipient of a grant from the Joseph $\mathrm{H}$. and Florence A. Roblee Foundation, St. Louis, Missouri, U.S.A.

The authors are grateful for the collaboration of $\mathrm{Dr}$ Richard I. Shader and for the editorial assistance of Ms Ann Werner.

Reprint requests should be addressed to Dr D.J. Greenblatt, Boston Collaborative Drug Surveillance Program, 400 Totten Pond Road, Waltham, MA 02154, U.S.A.
CHAPMAN, S.F. (1976). Psychotropic drug use in the elderly: public ignorance or indifference? Med. J. Aust., 2, 62-64.

DAWSON-BUTTERWORTH, K. (1970). The chemopsychotherapeutics of geriatric sedation. J. Am. Geriatr. Soc., $18,97-114$.

EVANS, J.G. \& JARVIS, E.H. (1972). Nitrazepam and the elderly. Br. med.J., 4, 487.

GIBSON, I.IJ.M. (1966). Barbiturate delirium. Practitioner, 197, 345-347.

GIRDWOOD, R.H. (1973). Nitrazepam nightmares. Br. med. J., $1,353$.

GOOSSENS, T., BULCKAERT, M. \& WAKELING, E. (1973). Nitrazepam and the subconscious. Br. med. J., 2, 488.

GREENBLATT, D.J., ALLEN, M.D. \& SHADER, R.I. (1977). Toxicity of high-dose flurazepam in the elderly: a report from the Boston Collaborative Drug Surveillance Program. Clin. Pharmac. Ther., 21, 355-361.

GREENBLATT, D.J. \& SHADER, R.I. (1974) Benzodiazepines in Clinical Practice. New York: Raven Press.

HARENKO, A. (1975). A comparison between chlormethiazole and nitrazepam as hypnotics in psychogeriatric patients. Curr. Med. Res. Opin., 2, 657-663.

JICK, H. (1974). Drugs-remarkably nontoxic. N. Engl. J. Med., 291, 824-828. 
KARIM, A.K.M.B., PRICE-EVANS, D.A. (1976). Polymorphic acetylation of nitrazepam. J. med. Genet., 13, 17-19.

KLOTZ, U., AVANT, G.R. \& HOYUMPA, A. (1975). The effects of age and liver disease on the disposition and elimination of diazepam in adult man. J. clin. Invest., 55, 347-359.

KOCH-WESER, J. \& SELLERS, E.M. (1976). Binding of drugs to serum albumin. N. Engl. J. Med., 294, 311-316, 526-530.

LEAROYD, B.M. (1972). Psychotropic drugs and the elderly patient. Med.J. Aust., 1, 1131-1133.

LEAROYD, B.M. (1974). Psychotropic drugs-are they justified? Med. J. Aust., 1, 474-479.

LE RICHE, W.H., CSIMA, A. \& DOBSON, M. (1966). A clinical trial of four hypnotic drugs. Can. med. Ass. J., 95, 300-302.

MALPAS, A. (1972). Subjective and objective effects of nitrazepam and amylobarbitone sodium in normal human beings. Psychopharmacologia, 27, 373-378.

MALPAS, A. \& JOYCE, C.R.B. (1969). Effects of nitrazepam, amylobarbitone and placebo on some perceptual, motor and cognitive tasks in normal subjects. Psychopharmacologia, 14, 167-177.

MALPAS, A., LEGG, N.J. \& SCOTT, D.F. (1974). Effects of hypnotics on anxious patients. Br. J. Psychiat., 124, 482-484.

MALPAS, A., ROWAN, A.J. \& JOYCE, C.R.B. (1970). Persistent behavioural and electroencephalographic changes after single doses of nitrazepam and amylobarbitone sodium. Br. med.J., 2, 762-764.

MEARES, R., MILLS, J.E. \& OLIVER, L.E. (1972). A clinical comparison of two non-barbiturate hypnotics, Mogadon and Mandrax. Med. J. Aust., 1, 266-268.

MILLER, R.R. \& GREENBLATT, D.J. (1976). Drug Effects in Hospitalized Patients: Experiences of the Boston Collaborative Drug Surveillance Program, 1966-1975. New York: John Wiley and Sons.

MOMOSE, T., ISHII, S. \& KUGE, T. (1976). Controlled comparison of estazolam and nitrazepam as hypnotics on the preoperative night sleep. Curr. Ther. Res., 19, 277-291.

RIEDER, J. \& WENDT, G. (1973). Pharmacokinetics and metabolism of the hypnotic nitrazepam. In The Benzodiazepines, Eds Garattini, S., Mussini, E. \& Randall, L.O., pp. 99-127. New York: Raven Press.

SHADER, R.I., GREENBLATT, D.J. \& HARMATZ, J.S. (1977). Absorption and disposition of chlordiazepoxide in young and elderly male volunteers. J. clin. Pharmac. 17, 709-718.

TAYLOR, F. (1973). Nitrazepam and the elderly. Br. med. J., $1,113-114$.

WALTERS, A.J. \& LADER, M.H. (1971). Hangover effect of hypnotics in man. Nature, 229, 637-638.

(Received April 24, 1977) 